\title{
Cerebral administration of alpha-synuclein monomers modulates inflammatory reaction in nigro-striatal system
}

\author{
Anna Sznejder-Pachołek', Ilona Joniec-Maciejak', Adriana Wawer' , Agnieszka Ciesielska², \\ Dagmara Mirowska-Guzel ${ }^{1,3}$ \\ ${ }^{1}$ Department of Experimental and Clinical Pharmacology, Centre for Preclinical Research and Technology (CePT), Medical \\ University of Warsaw, Poland \\ ${ }^{2}$ Gladstone Institutes of Neurological Disease, United States \\ ${ }^{3}$ Department of Neurology, Institute of Psychiatry and Neurology, Poland
}

Sznejder-Pachołek A, Joniec-Maciejak I, Wawer A, Ciesielska A, Mirowska-Guzel D. Cerebral administration of alpha-synuclein monomers modulates inflammatory reaction in nigro-striatal system. J Pre-Clin Clin Res. 2019; 13(1): 26-36. doi: 10.26444/jpccr/103772

\begin{abstract}
Introduction. It has been established that changes in the levels of a-synuclein (ASN) are associated with Parkinson's disease (PD). The progression of PD is characterized by immune response and inflammation, especially the activation of the microglia. Activated microglia cells release potentially cytotoxic substances, such as pro-inflammatory cytokines, caspases as well as neuroprotective molecules such as neurotrophins.

Objective. We examined the potential role of recombinant ASN monomers as a major pathogenic factor causing inflammatory responses in the central nervous system.

Methods. Mice were bilaterally infused with human ASN monomers into the striatum (ST) or substantia nigra pars compacta $(\mathrm{SNpc}$ ) (single treatment was $4 \mu \mathrm{g} /$ structure, $8 \mu \mathrm{g}$ per brain) and decapitated after 1,4 or 12 weeks post injection. The changes in the level of neurotrophins, receptor for neurotrophins, marker of microglia and adhesion molecules in ST were evaluated using Real-Time PCR. The analysis of morphological changes of T lymphocytes was performed by immunohistochemical staining.

Results. In our study, we reported a CD4+ T-cell infiltration to the CNS following ASN delivery to ST or SNpc. We observed a slight effect of ASN on the expression of intercellular adhesion molecule 1 (ICAM-1) and vascular cell adhesion molecule 1 (VCAM-1). The present study demonstrated an increase in the expression of the glial cell-derived neurotrophic factor (GDNF), brain-derived neurotrophic factor (BDNF), neurotrophin-3 (NT-3) and receptors of nerve growth factor (NGF) - TrkA, receptor of BDNF - TrkB, receptor of NT-3 - TrkC, following the administration of ASN into ST.

Conclusion. Our research provides further evidence for the involvement of ASN in the inflammatory response in the CNS.

\section{Key words}

Parkinson's disease, Alpha-synuclein, Neurotrophins, Gliosis, Adhesion Molecules, Neuroinflammation

\section{Abbreviations}

ASN, alpha-synuclein; BDNF, brain-derived neurotrophic factor; CNS, central nervous system; GAPDH, glyceraldehyde 3-phosphate dehydrogenase; GDNF, glial cell-derived neurotrophic factor; ICAM Intercellular Adhesion Molecule 1; Iba1, ionized calcium binding adaptor molecule 1; IFNy, interferon gamma; IL, interleukin; LBs, Lewy bodies; LFA-1, Lymphocyte functionassociated antigen 1 - integrin; MPP+, 1- methyl-4-phenylpyridinium; MPTP, 1-methyl-4-phenyl-1,2,3,6-tetrahydropyridine; NGF, nerve growth factor; NT-3, neurotrophin-3; PD, Parkinson's disease; Real-Time PCR, Real-Time polymerase chain reaction; SNpc, substantia nigra pars compacta; $\mathrm{ST}$, striatum; TGF $\beta$, transforming growth factor beta; TNFa, tumor necrosis factor alpha; TH, tyrosine hydroxylase; TrkA (NGF receptor); TrkB (BDNF receptor); TrkC (NT-3 receptor); VCAM-1, Vascular Cell Adhesion Molecule 1
\end{abstract}

\section{INTRODUCTION}

Parkinson's disease (PD) is a neurodegenerative disorder characterized by progressive loss of dopaminergic neurons in the substantia nigra pars compacta (SNpc) and aggregation of alpha synuclein (ASN) along with sustained neuroinflammation. ASN may contribute to PD pathogenesis in a number of ways. Some evidence suggests that ASN accumulation in astrocytes might damage these cells in Address for correspondence: Ilona Joniec-Maciejak, Department of Experimental and Clinical Pharmacology, Centre for Preclinical Research and Technology (CePT), Medical University of Warsaw, Banacha 1B, 02-097, Warsaw, Poland

E-mail: ilona.joniec@wum.edu.pl

Received: 14 November 2018; Accepted: 6 February 2019; first published: 21 March 2019
SNpc and promotes the degeneration of dopaminergic (DA) neurons [1]. Ours and other studies indicate that there is a link between the increased ASN concentration and the activation of microglia cells [2]. In our previous study we observed striatal activation of microglia cells and increased expression of some inflammatory cytokines, such as interleukin 1 alpha (IL-1a), tumor necrosis factor alpha (TNFa) and interferon gamma (IFNg), after injection of ASN [3]. Other results suggest that modified, aggregated or overexpressed ASN can play a key role in microglial activation, inducing the expression of pro-inflammatory cytokines, and can contribute to the advancement of PD [4-7]. Currently available antiparkinsonian treatments are unable to arrest the degenerative process. 
Neurotrophins such as brain-derived neurotrophic factor (BDNF), glial cell-derived neurotrophic factor (GDNF) or nerve growth factor (NGF) are involved in the development and survival of already mature DA neurons. Moreover, neurotrophic factors may promote the restoration of the function of DA neurons and protect them from ongoing degeneration. GDNF was originally characterized as a growth factor that promoted the survival of ventral midbrain DA neurons [8]. In animal studies, it was shown that GDNF protects dopaminergic cells in 6-hydroxydopamine (6OHDA) and 1-methyl-4-phenyl-1,2,3,6-tetrahydropyridine (MPTP) induced PD models $[9,10]$. Gill et al. performed a treatment using a recombinant protein monomer containing GDNF as a potent trophic factor for nigral DA neurons [11]. Ciesielska et al. observed the changes in the natural course of PD under the infusion of GDNF by viral vector infusion into ST [12]. BDNF is a member of the nerve growth factors (NGF) family that also includes neurotrophin-3 (NT-3) and is widely present in the central nervous system (CNS), especially in the hippocampus. It has been demonstrated that the reduction of BDNF is involved in the pathogenesis of PD, but its mechanism is not clear [4]. BDNF, NGF and NT-3 all support the survival of the subpopulations of sensory neurons of neural crest-derived cells as well as cholinergic and dopaminergic neurons $[13,14]$. Hyman et al. used mouse embryonic stem cells to study neurotrophins and their receptors as tools to dissect mechanisms that are relevant both to development and neurodegeneration. They suggest that the signaling of neurotrophins is critical to the survival of dopaminergic neurons during the development of SNpc [13]. Moreover, in adult brain, neurotrophins are crucial for synaptic plasticity and memory processing $[15$, 16]. Weinstein et al. suggest that higher serum BDNF levels may protect against a future occurrence of dementia and $\mathrm{AD}$ [17]. It is known that BDNF, GDNF, NGF, NT-3, Trk A (NGF receptor),TrkB (BDNF receptor), and TrkC (NT-3 receptor) expression must occur as a neural response to injury $[18,19]$. The biological effects of NGF, BDNF, GDNF, NT-3 and other neurotrophins are directly dependent on their initial binding to specific cell surface receptors: Trk and p75 neurotrophin (p75) [20]. P75 glycoprotein is also known as the pan-neurotrophin receptor because it can also bind with neurotrophins other than NGF [21]. Santos et al. suggest that cannabidiol induces neuritogenesis by activating TrkA receptors, independently of NGF. The authors found out that the neuroprotective properties of cannabidiol might be beneficial in PD. Its neuritogenic effect was not dependent on NGF, but it was inhibited by TrkA inhibitor. Cannabidiol did not increase the expression of NGF, but protected against its decrease induced by 1- methyl-4-phenylpyridinium (MPP+), probably by an indirect mechanism. In neurons, the main pathway regulating apoptosis seems to be mediated by growth factors and Trk receptors [22]. The physical exercise in MPTP [23] or 6-OHDA [24] intoxication in a mice model of PD influenced the increase in the level of BDNF factor in SNpc. The authors also noted that the exercise restored the neurotoxin-related reduction of TrkB receptor expression in the striatum and hippocampus. The binding of neurotrophins with Trk receptors plays an important role in neurodegenerative diseases. By observing these bonds, one may have an insight into research on the specificity of action and the therapeutic potential of specific neurotrophic factors.
Sobue et al. also observed that the increased mRNA level for NGF, BDNF, NT-3 is proportional to the invasion by $\mathrm{T}$ cells [25]. Immune cells express BDNF and NT-3, and their receptors TrkB and TrkC [26]. Moreover, abnormal secretion of signaling neurotrophins should be associated with the increased degeneration and vulnerability to injury $[27,28]$. $\mathrm{BDNF}$ is involved in inflammation. This neurotrophin is found in the activated microglia [29]. Activated T and B human cells secrete BDNF in vitro. Moreover, the secretion of BDNF is increased in CD4+ cells lines [30]. GDNF and NGF are well known to be potent neurotrophic factors supporting the survival of DA neurons of SNpc in vitro and in vivo. It has been observed that inflammatory responses and mechanical damage contribute to a significant impairment of NGF expression in glial cells. These data suggest that microglia and astroglia cells are the primary sources of neurotrophins in injury [31, 32]. McGeer et al. suggest that astrocytes can recruit and stimulate the activation of microglia cells, thus demonstrating pro-inflammatory activity, supporting the neurodegenerative process, as well as (similar to microglia) secreting anti-inflammatory agents into the environment, including neurotrophic factors affecting the survival and repair of damaged dopaminergic neurons (eg. GDNF, BDNF) [33]. Leukocytes, including T-cells (CD3 + and CD4 +) and $\mathrm{B}$ lymphocytes, were observed to express the ability to secrete NGF [34]. Both NGF and NGF-specific receptors are dynamically regulated in leucocytes and their expression is enhanced by an inflammatory response or other stimulation [35]. It was demonstrated that BDNF and other neurotrophins, such as NGF, NT-3 and NT-4/5, showed beneficial effects in acute or chronic neurodegenerative diseases.

Kurkowska-Jastrzębska et al. pointed out to the immune reaction post MPTP intoxication in mice model of PD. They observed infiltration of CD4+ and CD8+ T cells in SNpc and ST. Moreover, many activated lymphocytes were present, showing an increased expression of the lymphocyte functionassociated antigen 1 (LFA-1). Kurkowska-Jastrzębska et al. found that the expression of the intercellular adhesion molecule 1 (ICAM-1) increased on the endothelium and appeared on the microglia in the injured regions [36]. ICAM-1 is produced by the cells of the immune system [37]. Leukocyte infiltration is also associated with the presence of vascular cell adhesion molecule 1 (VCAM-1). Wu et al. also noted that the increased activation of the endothelial cells is linked with the increase of the activity of adhesion molecules VCAM-1 and ICAM-1 as well as with their endothelium-mediated adhesion and the migration of neutrophils from the blood into the tissue [38].

In the present study we investigated the influence of the intracerebral administration of human ASN into the nigrostriatal system on the levels of neurotrophins (BDNF, GDNF, NGF, NT-3) and their receptors (Trk A, TrkB, TrkC). We also examined the effect of ASN injection on VCAM-1 and ICAM-1 and infiltration of CD4+ T lymphocytes into the CNS. Finally, we verified the effect of ASN injection on microglia activation by measuring the level of mRNA for Iba-1.

\section{MATERIALS AND METHODS}

One year-old male C57BL/10 Tar mice were used in this study. The animals were housed in standard laboratory 
conditions under 12-h light/dark cycle (7:00 a.m./7:00 p.m.), at a controlled temperature $\left(22 \pm 5^{\circ} \mathrm{C}\right)$ and at a humidity of $60 \pm 5 \%$. All mice had free access to food and water. Each experimental group comprised 12 animals. The experimental reports were approved by the 2 nd Local Ethics Committee in Warsaw and the experiments were conducted in accordance with the National Institutes of Health Guide for the Care and Use of Laboratory Animals and in accordance with the EU Directive 2010/63/EU on animal experiments. All efforts were made to reduce the number of animals used and to minimize animals suffering.

\subsection{Intracerebral ASN administration (stereotactic surgery)}

After surgical anesthesia (ketamine: xylazine, 1:1, $2 \mathrm{ml} / \mathrm{kg}$ ), the animals were put in a stereotactic frame (Stoelting, USA). The mice were bilaterally infused with $\mathrm{ASN}$ or $\mathrm{NaCl}$ into ST or SN at a flow rate of $0.5 \mathrm{ml} / \mathrm{min}$ with a programmable microsyringe pump (World Precision Instruments, USA) using the following stereotactic coordinates: AP: +0.62 , ML: 1.75 relative to bregma and $\mathrm{DV}:-3.5 \mathrm{~mm}$ relative to dura (ST) as well as AP: -3.08 , ML: \pm 0.75 relative to bregma and DV: $-4.5 \mathrm{~mm}$ relative to dura (SN), according to the protocol described earlier by Sznejder-Pachołek [3]. The single ASN treatment dosage was $4 \mu \mathrm{l}(4 \mu \mathrm{g})$ per structure (8 $\mu \mathrm{g} /$ brain). The ASN protein (product No. S7820; SigmaAldrich, USA) was dissolved in a sterile saline solution $(0.9 \%$ $\mathrm{NaCl})(1 \mathrm{mg} / \mathrm{ml})$. The applications diagram is provided in Table 1.

Table 1. A diagram of ASN and $\mathrm{NaCl}$ applications

\begin{tabular}{|c|c|c|c|}
\hline intervention & structure & time point & Group (n) \\
\hline control without any treatment & & & Control (12) \\
\hline \multirow[t]{6}{*}{$0.9 \% \mathrm{NaCl}$} & SN & 1 week & $\mathrm{NaCl}$ SN 1w (12) \\
\hline & & 4 weeks & $\mathrm{NaCl} \mathrm{SN} \mathrm{4w} \mathrm{(12)}$ \\
\hline & & 12 weeks & $\mathrm{NaCl} S N 12 \mathrm{w}(12)$ \\
\hline & ST & 1 week & $\mathrm{NaCl}$ ST 1w (12) \\
\hline & & 4 weeks & $\mathrm{NaCl}$ ST 4w (12) \\
\hline & & 12 weeks & $\mathrm{NaCl}$ ST $12 \mathrm{w}(12)$ \\
\hline \multirow[t]{6}{*}{ ASN solution (1 mg/ml) } & SN & 1 week & ASN SN 1w (12) \\
\hline & & 4 weeks & ASN SN 4w (12) \\
\hline & & 12 weeks & ASN SN 12w (12) \\
\hline & ST & 1 week & ASN ST 1w (12) \\
\hline & & 4 weeks & ASN ST 4w (12) \\
\hline & & 12 weeks & ASN ST 12w (12) \\
\hline
\end{tabular}

\subsection{Tissue preparation}

For the Real-Time PCR method, the animals were euthanized by cervical dislocation and decapitated. Upon removal of the brain, the striata were dissected and immediately frozen.

For the immunohistochemical method, the animals (6 per group) were anaesthetised with an anaesthetic solution (ketamine: xylazine, 1:1,2 ml/kg) and transcardially perfused with a heparinised $0.9 \% \mathrm{NaCl}$ solution followed by $10 \%$ paraformaldehyde-lysine periodate fixative (PLP). The brains were removed, post-fixed in PLP for 4-6 h, then immersed in a $20 \%$ sucrose solution overnight at $4-8^{\circ} \mathrm{C}$ and rapidly frozen.

\subsection{Real-Time PCR (Real-Time polymerase chain reaction)}

The mRNA expression for Ibal, NGF, BDNF, NT-3, TrkA, TrkB, VCAM-1, ICAM-1 genes in the striata was evaluated using Real-Time PCR according to the method described earlier by Sznejder-Pachołek [3]. Total RNA was extracted from the brain tissue using the TRI reagent (Sigma-Aldrich, USA), in accordance with the manufacturer's instructions. The concentration of isolated RNA was determined spectrophotometrically at $260 \mathrm{~nm}$. Reverse transcription was carried out by incubation at $+42^{\circ} \mathrm{C}$ for $1 \mathrm{~h}$ with Moloney murine leukemia virus (MMLV), reverse transcriptase was performed according to the instructions of the reagent's manufacturer (Sigma-Aldrich, USA). Following the reverse transcription reaction, $\mathrm{cDNA}$ products were stored at $-20^{\circ} \mathrm{C}$ until use. The $\mathrm{cDNA}$ was amplified with gene-specific primers (Table 2) designed using Primer-BLAST software (NCBI, USA).

Table 2. Sequences of gene specific primers used in Real-Time PCR. F-forward, R-reverse

\begin{tabular}{|c|c|c|c|}
\hline Target gene & & Sequences of gene-specific primers $\left(5^{\prime}->3^{\prime}\right)$ & Product length \\
\hline \multirow[t]{2}{*}{ GAPDH } & $\mathrm{F}$ & 5' CTITGGCATTGTGGAAGGGC 3' & 125 \\
\hline & $\mathrm{R}$ & 5' CAGGGATGATGTTCTGGGCA 3' & \\
\hline \multirow[t]{2}{*}{ Iba1 } & $\mathrm{F}$ & 5' GCTIITGGACTGCTGAAGGC 3' & 106 \\
\hline & $\mathrm{R}$ & 5' GTTTGGACGGCAGATCCTCA 3' & \\
\hline \multirow[t]{2}{*}{ BDNF } & $\mathrm{F}$ & 5' CCGAGCTCATCTTTGCCAGA 3' & 142 \\
\hline & $\mathrm{R}$ & 5' CTGTCACTGAGCCCTAGCAC 3' & \\
\hline \multirow[t]{2}{*}{ NGF } & $\mathrm{F}$ & 5' AGCCAGTGAAATTAGGCTCCC 3' & 129 \\
\hline & $\mathrm{R}$ & 5' TATTGGGCCCAGACACTGAG 3' & \\
\hline \multirow[t]{2}{*}{ GDNF } & $\mathrm{F}$ & 5' GTCCAGACACAGCCTCTAGC $3^{\prime}$ & 109 \\
\hline & $\mathrm{R}$ & 5' AAACTITACCCTGCTGCGGA 3' & \\
\hline \multirow[t]{2}{*}{ NT-3 } & $\mathrm{F}$ & 5' CCTCTITCTाTCTTCCCCTCGT 3' & 139 \\
\hline & $\mathrm{R}$ & 5' CCATGGCATCCGTGTGACTA 3' & \\
\hline \multirow[t]{2}{*}{ TrkA } & $\mathrm{F}$ & 5' TCAAGCGCCAGGACATCATT 3' & 118 \\
\hline & $\mathrm{R}$ & $5^{\prime}$ TTGACAGCCACGAGCATCTT 3' & \\
\hline \multirow[t]{2}{*}{ TrkB } & $\mathrm{F}$ & $5^{\prime}$ TACTACAGGGTGGGAGGACAC 3' & 94 \\
\hline & $\mathrm{R}$ & 5' CTCTGTGGTGAACTTCCGGT 3' & \\
\hline \multirow[t]{2}{*}{ TrkC } & $\mathrm{F}$ & $5^{\prime}$ TACTACAGGGTGGGAGGACAC 3' & 84 \\
\hline & $\mathrm{R}$ & 5' CTCTGTGGTGAACTTCCGGT 3' & \\
\hline \multirow[t]{2}{*}{ ICAM 1} & $\mathrm{~F}$ & $5^{\prime}$ TGTCAGCCACCATGCCTTAG 3' & 132 \\
\hline & $\mathrm{R}$ & 5' CAGCTTGCACGACCCTTCTA 3' & \\
\hline \multirow[t]{2}{*}{ VCAM 1} & $\mathrm{~F}$ & 5' CCCAGGTGGAGGTCTACTCA 3 & 77 \\
\hline & $\mathrm{R}$ & 5' GACAGGTCTCCCATGCACAA 3' & \\
\hline
\end{tabular}

As a control to eliminate sample-to-sample differences in RNA extraction and conversion to cDNA, we amplified the housekeeping gene in each sample (glyceraldehyde 3-phosphate dehydrogenase; GAPDH). PCR mixtures contained $1 \mu \mathrm{l}$ of cDNA along with $2 \mu \mathrm{l}$ of $5 \mathrm{x}$ HOT FIREPol $^{\oplus}$ EvaGreen ${ }^{\circledast}$ qPCR Mix Plus (Solis BioDyne, Estonia) and $1 \mu \mathrm{l}(10 \mathrm{mM})$ of each primer in a total reaction volume of $10 \mu \mathrm{l}$. The amplification protocol was as follows: initial denaturation at $94^{\circ} \mathrm{C}$ for $2 \mathrm{~min} ; 36-42$ cycles at $94^{\circ} \mathrm{C}$ for $15 \mathrm{~s}, 61^{\circ} \mathrm{C}$ for $30 \mathrm{~s}$, and $72^{\circ} \mathrm{C}$ for 1 min using Rotor-Gene $\mathrm{Q}$ 5plex HRM System (QIAGEN Research, Inc., Netherlands). Melting curve analysis was performed at the end of each PCR assay for specificity control, by measuring the emission of $5 \mathrm{x}$ HOT FIREPol ${ }^{\varpi}$ EvaGreen (Solis BioDyne, Estonia) at $515 \mathrm{~nm}$ from 65 to $90^{\circ} \mathrm{C}$ every $0.5^{\circ} \mathrm{C}$. All amplifications were carried out in triplicates. GAPDH was used for the normalisation of expression levels of all genes. The relative expression of 
the genes was calculated by estimation according to Pfaffl et al. [39].

\subsection{Immunohistochemical staining}

Horizontal sections $(20 \mu \mathrm{m})$ of ST and SN were cut on a cryostat, transferred onto gelatinised slides and stored at $-20^{\circ} \mathrm{C}$ until further processed. The frozen sections were dried at room temperature and rinsed in phosphate buffered saline (PBS) containing $0.1 \%$ Triton X 100 (Sigma-Aldrich, USA). The sections were incubated for 90 min with antibodies to: CD3+ (rat anti-CD3 antibody, AbDSerotec, USA), CD4+ (rat anti-CD4 antibody, AbDSerotec, USA) or CD8+ (rat anti-CD8 antibody, AbDSerotec, USA). The antibodies to $\mathrm{CD} 3+, \mathrm{CD} 4+$ or CD8+ were diluted 1:500 in 0.1 M PBS with $0.1 \%$ goat serum and $0.1 \%$ Triton X 100 followed by a $2 \mathrm{~h}$ incubation with secondary rabbit anti-rat antibody (Vector, USA). The binding of the primary antibody was revealed by the avidin-biotin-peroxidase DAB method (Vectastain kit, Vector, USA). The slides were dehydrated, cleared in xylene and mounted. The sections were examined with an Olympus BX53 microscope in conjunction with Olympus CAST software (Olympus, Denmark).

\subsection{Statistical analysis}

Data were analyzed using STATISTICA 10.0 software (StatSoft, Poland). The differences between the groups were examined by the Kruskal-Wallis one-way analysis of variance followed by the Mann-Whitney $U$ test. The results were considered statistically significant at $p<0.05$. All data are shown as mean value and standard error of the mean (SEM).

\section{RESULTS}

The most important aspect of this research is the comparison between the ASN groups and $\mathrm{NaCl}$ groups.

\section{1 Lymphocyte brain infiltration}

The CD4+ lymphocytes were observed throughout the cross section after ASN injection, but the highest concentration was observed after ASN intoxication in the ST or SNpc area (Fig. 1, Fig. 2). These cells displayed a typical lymphocyte morphology, showing small cytoplasmic volume. Importantly, the quantitative analysis revealed a significant increase in the number of CD4+ T cells in all time points (except for 12 weeks-time point) after injection of ASN into $\mathrm{SN}$ or ST compared to the $\mathrm{NaCl}$ groups and control group. The injection of $\mathrm{NaCl}$ to ST caused a significant increase the number of CD4+ T lymphocytes only after 1 week (Fig. 3)

\subsection{Real-Time PCR}

\subsubsection{Iba1}

Real-Time PCR showed a significant increase in the striatal Ibal mRNA expression after ASN injection into ST or SN in all groups compared to the control group. The increase was detected 4 and 12 weeks after ASN injection to ST compared to the $\mathrm{NaCl}$ group. After the injection of ASN to SN we observed a significant elevation in the level of Iba1 mRNA 12 weeks after ASN injection compared to the corresponding $\mathrm{NaCl}$ group. $\mathrm{NaCl}$ injection into ST caused an increase in the Ibal mRNA level expression only at 1 week compared to the control. $\mathrm{NaCl}$ injection into $\mathrm{SN}$ showed a significantly elevated level of Iba1 mRNA at 1 week and 4 weeks compared to the control group (Fig. 4A).

\subsubsection{BDNF}

Real-Time PCR analysis revealed the striatal increase or induction of the mRNA expression of NGF, BDNF, NT-3 and their receptors TrkA, TrkB after ASN administration to ST or SN. A significant increase in the striatal BDNF mRNA expression was detected 4 and 12 weeks after ASN injection to ST compared to the $\mathrm{NaCl}$ and control group. ASN intoxication of SN had no effect on the striatal BDNF mRNA level at any group in comparison to the corresponding $\mathrm{NaCl}$ group or control group. $\mathrm{NaCl}$ injection into ST caused an increase in the striatal BDNF mRNA level expression only at 1 week compared to the control group (Fig. 4B).

\subsubsection{NGF}

Striatal NGF mRNA level was significantly elevated at 1 week - time points with a peak at 12 week time points after ASN injection into $\mathrm{SN}$ in comparison to the $\mathrm{NaCl}$ and control group. After ASN injection into ST, the striatal NGF mRNA level was significantly elevated at 4 and 12 weeks-time points compared to the control group (Fig 4C).

\subsubsection{GDNF}

ASN injection caused a significant increase of the striatal GDNF mRNA expression after 4 weeks and 12 weeks from administration into ST or SN. Striatal GDNF mRNA level was significantly elevated at 4 weeks after ASN injection into ST or SN in comparison to the control group. (Fig. 4D)

\subsubsection{NT-3}

NT-3 mRNA level was significantly elevated at 4 weeks and 12 weeks after ASN administration into ST compared to the corresponding $\mathrm{NaCl}$ groups. Real-Time PCR showed a significant increase in the striatal NT-3 mRNA level expression after ASN injection into ST in all time points in comparison to the control group. We did not see any effect of ASN injection into SN on the NT-3 mRNA level in comparison with the $\mathrm{NaCl}$ groups. $\mathrm{NaCl}$ injection into ST caused an increase in the striatal NT-3 mRNA level expression at 1 week compared to the control group and decreased in the striatal mRNA level expression at 4 weeks in comparison with the control group (Fig. 4E).

\subsubsection{TrkA}

ASN administration to ST led to an increase in the striatal TrkA mRNA expression at 12 weeks after the injection compared with the corresponding $\mathrm{NaCl}$ groups and control group. ASN injection to ST caused also a significant increase of the striatal TrkA mRNA expression in SN at all time points compared to the control. In the $\mathrm{NaCl}$ group, we detected a significant increase in TrkA mRNA expression only once, 1 week after $\mathrm{NaCl}$ injection into $\mathrm{SN}$ (Fig. 4F).

\subsubsection{TrkB}

The increase in the TrkB mRNA level was noticed 12 weeks after the injection compared with the corresponding $\mathrm{NaCl}$ groups. ASN administration to ST led to an increase in the striatal TrkB mRNA expression at 4 weeks and 12 weeks after the injection of ASN to ST in comparison to the control group. We observed the same 4 weeks and 12 weeks after ASN injection into $\mathrm{SN}$ in comparison to the control group. 


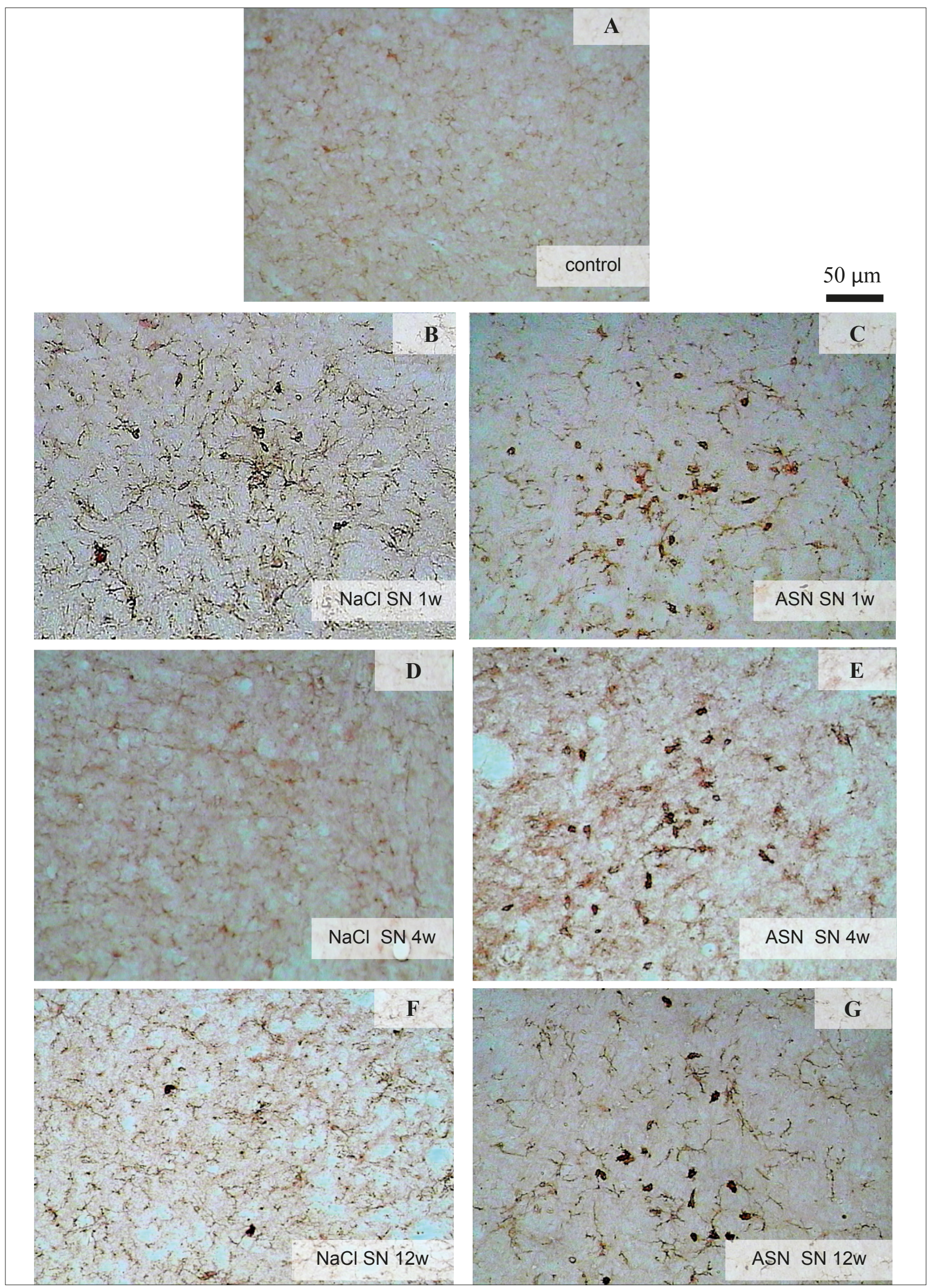

Figure 1. CD4+ lymphocyte infiltration into mouse brains (stained with anti-CD4+ antibody) in mouse $S N$ after NaCl (B, D, F) or ASN (C, E, G) injection. Magnification $\times 200$ 


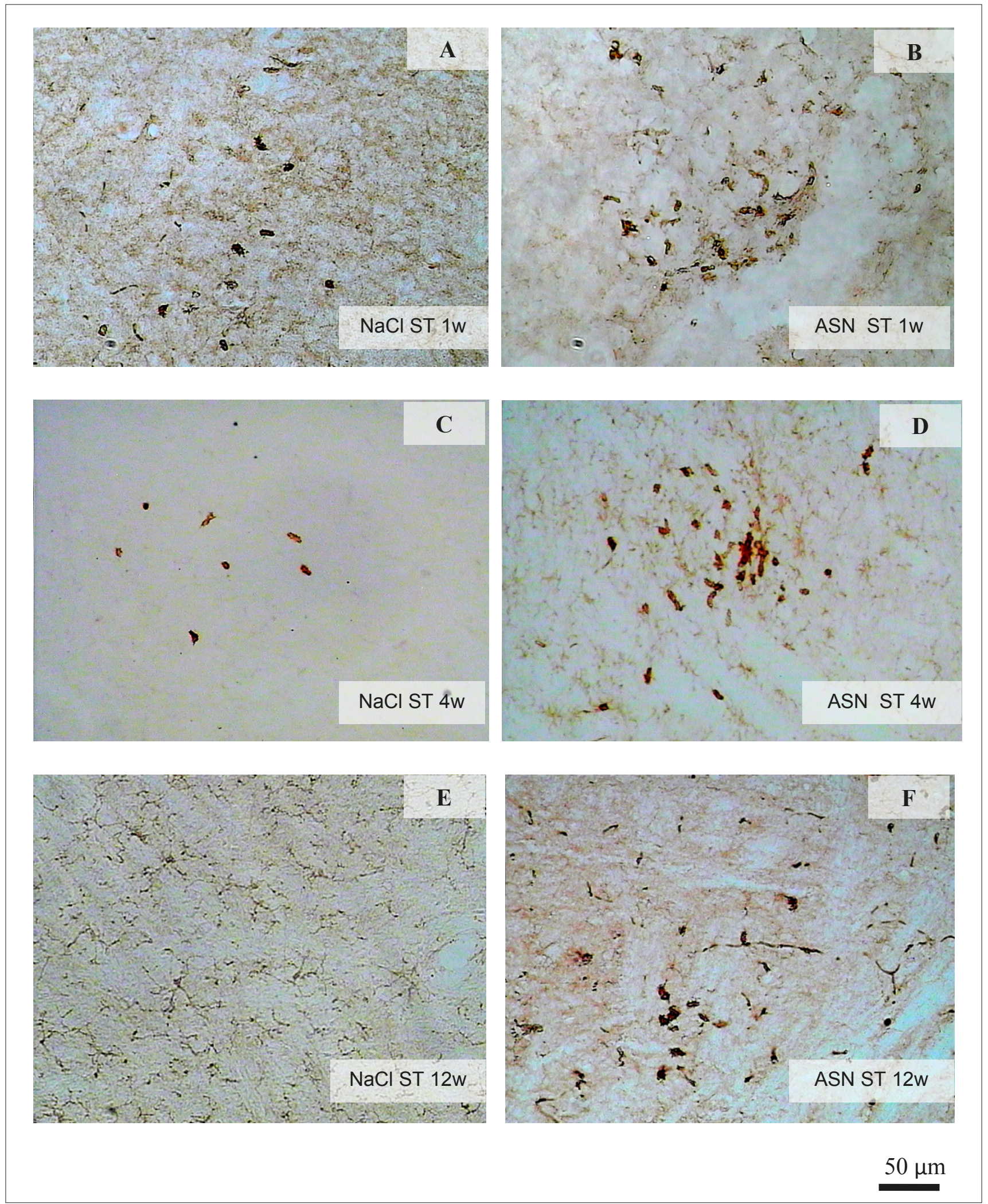

Figure 2. CD4+ lymphocyte infiltration in mouse brains (stained with anti-CD4+ antibody) in mouse ST after $\mathrm{NaCl}(\mathrm{A}, \mathrm{C}, \mathrm{E})$ or $\mathrm{ASN}(\mathrm{B}, \mathrm{D}, \mathrm{F})$ injection. Magnification $\times 200$

In the $\mathrm{NaCl}$ group, we detected a significant increase in $\mathrm{TrkB}$ mRNA expression only once, 1 week after $\mathrm{NaCl}$ injection into ST or SN (Fig. 4G).

\subsubsection{TrkC}

TrkC mRNA level was significantly elevated at 4 weeks and 12 weeks after ASN administration into ST compared to the corresponding $\mathrm{NaCl}$ groups and control group. RealTime PCR showed a significant increase in the striatal TrkC mRNA expression after 12 weeks from ASN injection into SN 


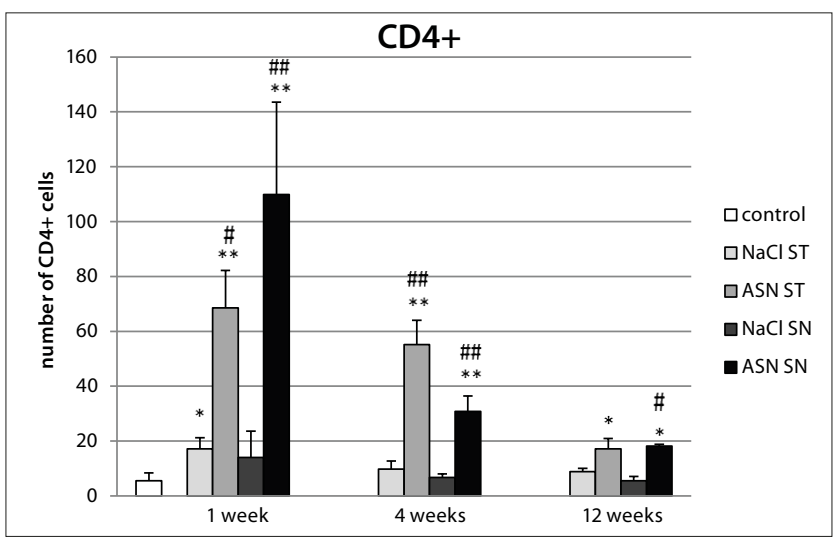

Figure 3. Quantification of the total number of infiltrated CD4+ T cells in SN or ST from ASN-treated mice * Differs from the control group * $p<0.05 * * p<0.01$; Differs from the corresponding $\mathrm{NaCl}$ group \# $\mathrm{p}<0.05, \# \mathrm{p}<0.01$ (Mann-Whitney $\mathrm{U}$ test)
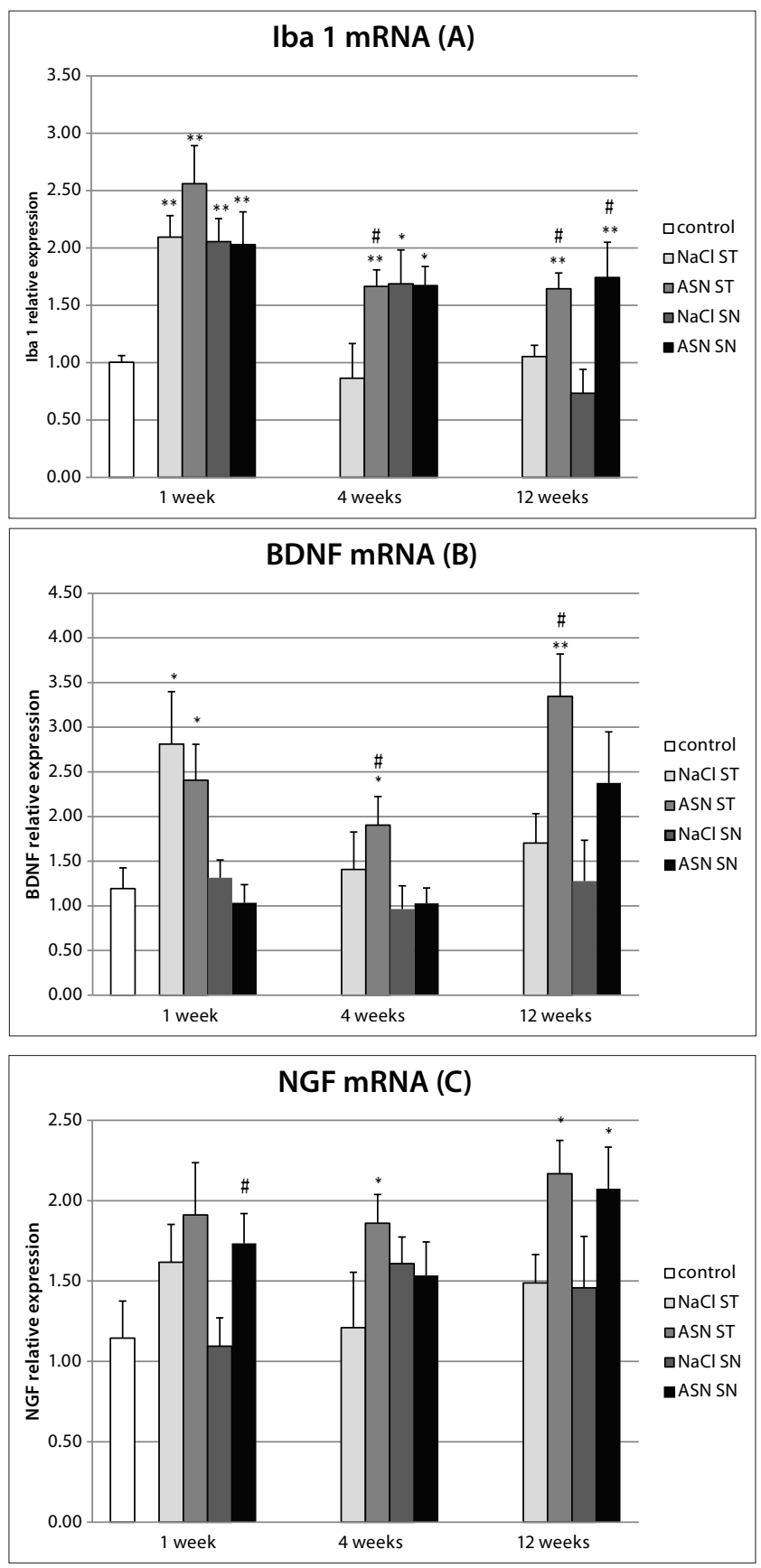
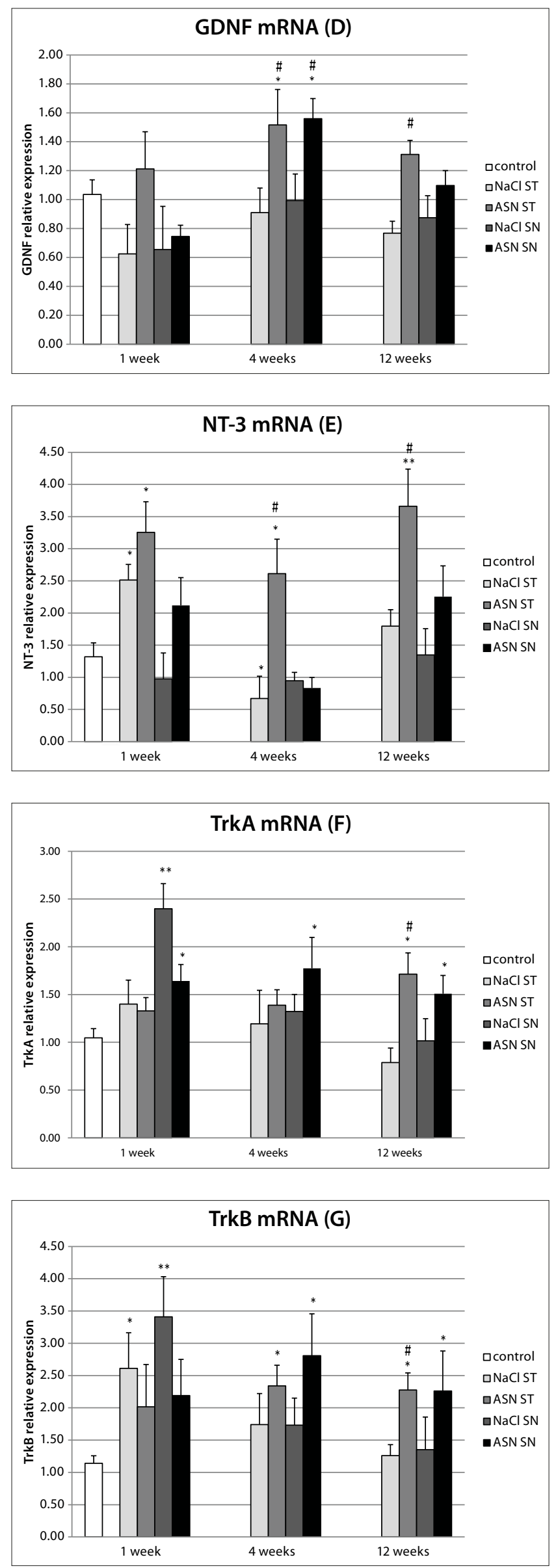

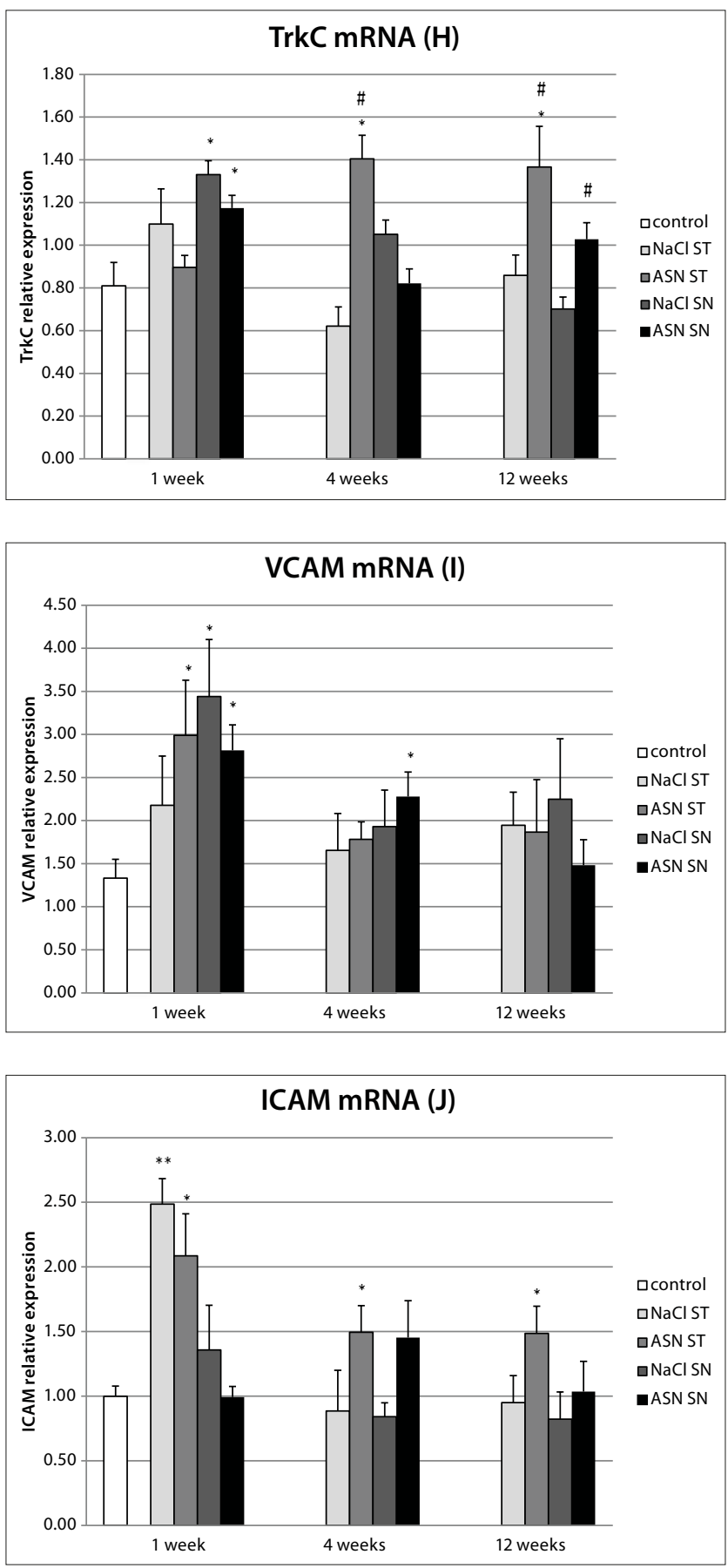

Figure 4. Expression of the Iba1 (A), BDNF (B), GDNF (C), NGF (D), NT-3 (E), TrkA (F), $\operatorname{TrkB}(\mathrm{G}), \operatorname{TrkC}(\mathrm{H}), \operatorname{VCAM}(\mathrm{I}), \mathrm{ICAM}(\mathrm{J})$ mRNA in the mice striatum. Data are presented as means + SEM of 5-6 mice per group. Groups of animals: control - no inference $\mathrm{NaCl}$ ST or SN - saline injections to the striatum (ST) or substantia nigra (SN) and sacrificed at 1, 4 or 12 weeks after saline injections; ASN ST or SN - a-synuclein was bilaterally administered to ST or SN and the animals were sacrificed at 1, 4 or 12 weeks following the administration. * Differs from the control group * $p<0.05$ **p $<0.01$; \# Differs from the corresponding $\mathrm{NaCl}$ group. \# $\mathrm{p}<0.05$, \#\#p $<0.01$ (Mann-Whitney $\mathrm{U}$ test)

compared to the $\mathrm{NaCl}$ group. $\mathrm{NaCl}$ injection into $\mathrm{SN}$ caused an increase in the striatal TrkC mRNA expression at 1 week compared to the control group (Fig. $4 \mathrm{H}$ ).

\subsubsection{VCAM-1}

There were no significant differences in the striatal VCAM1 mRNA expression between the $\mathrm{NaCl}$ group and the corresponding ASN group. 1 week after ASN injection into
ST we observed an increased level of the striatal VCAM-1 gene expression only in comparison with the control group. After 1 week and 4 weeks of ASN injection to SN we observed a significant increase of the VCAM-1 mRNA level $v$ s. control group. Moreover, after $\mathrm{NaCl}$ injection to $\mathrm{SN}$ we noticed a peak of striatal VCAM-1 mRNA only at 1 week (Fig. 4I).

\subsubsection{ICAM-1}

We did not see any effect of ASN injection into ST or SN on the ICAM-1 mRNA level in comparison to the corresponding $\mathrm{NaCl}$ groups. The increase of the striatal ICAM-1 mRNA expression was observed 1 week after $\mathrm{NaCl}$ injection into ST $v s$. control group. Striatal ICAM-1 mRNA level was significantly elevated after the injection of ASN only compared to the control group at all time points after ASN injection into ST (Fig 4J).

\section{DISCUSSION}

The progression of PD is accompanied by an inflammatory response. The relationship between ASN and microglial activation, infiltration of lymphocytes and the changes in the level of neurotrophins have attracted researchers' attention. The development of an inflammatory reaction includes: the stimulation of microglial and astroglial cells, the production of acute phase proteins, adhesion molecules, chemokines, cytokines and the infiltration of peripheral blood leukocytes to the lesion site [40-44].

An interesting finding in the current study is that ASN has a significant effect on the mRNA expression of neurotrophins and the level of their receptors. A reduced level of neurotrophins is observed in neurodegenerative diseases $[17,18]$. In our study, we demonstrated an increase in the expression of the BDNF, GDNF and NT-3 mRNA level at 4 and 12 weeks after the administration of ASN to ST. The presence of T cells, whose infiltration has been demonstrated in groups where ASN was given, might be responsible for an increased BDNF expression. Under physiological conditions, neurons are the source of neurotrophins in the CNS. In addition to neurons, the ability to produce BDNF is also demonstrated by mouse $\mathrm{T}$ lymphocytes, human $\mathrm{T}$ and $\mathrm{B}$ cells, and monocytes [30]. Studies on nerve cell cultures conducted by Yuan et al. showed that ASN overexpression led to a decrease in BDNF expression. The authors find it to be significant in the pathophysiology of PD. In addition, they observed that ASN overexpression resulted in a decrease in the activity of protein kinase $C$ whose dysfunction had been observed in patients with PD [45]. The above findings indicate that the overexpression of ASN not only leads to a decrease in BDNF levels, but also, by decreasing the activity of protein kinase $\mathrm{C}$, indirectly contributes to the inhibition of neuroprotective processes. This study demonstrated an increased expression of the BDNF, GDNF and NT-3 genes at 4 and 12 weeks after the administration of ASN to ST, which may appear contrary to the study of Yuan et al. [46]. Four weeks after the administration of ASN, we observed a strong increase in CD4+ lymphocyte infiltration, which may be the source of the increased expression of BDNF mRNA. Moreover, after 12 weeks from the injection of ASN, the higher level of mRNA for BDNF and GDNF was still observed, although we did not notice the increased migration of $\mathrm{CD} 4+$. We demonstrated an increase in the expression 
of the receptor for the NGF (TrkA) gene, receptor for the BDNF (TrkB) gene, and receptor for the NT-3 (TrkC) gene at 12 weeks from the administration of ASN to ST. At that time, we also observed an increased level of Ibal mRNA the indicator of microglial activation. GDNF is originally synthesized as a prepropeptide mainly in glial cells [47]. Based on our study, it can be concluded that the increased expression of trophic factor mRNA is associated with the microglial cell activation and the infiltration of stimulated T CD4+ lymphocytes, which could be the source of the neurotrophins. It suggests that ASN monomers probably enhance the expression of trophic factors indirectly by mediating inflammatory markers. Moreover, in our study, during the first stage (until week 12) after the administration of ASN to the CNS, microglial cell activation and a response from neuronal cells could be observed, which could further enhance, inter alia, the expression of trophic factors and their receptors. It is likely that the long-lasting ASN overexpression in PD may lead to damage or inhibition of the secretion pathway of neurotrophic factors or receptors, accounting for a decrease in the level of neurotrophins in patients with PD.

In our study, we did not confirm an increase in NGF mRNA expression after the administration of ASN to ST. We noticed an increase in gene expression for NGF only in the first week after the administration of ASN to SN, however, in the subsequent time points we could see some tendency for an increase in mRNA level for NGF. As previously demonstrated, an increase in the expression of the receptor for NGF (TrkA) was noted after 12 weeks from the injection of ASN. After 12 weeks of the intoxication with ASN, we could possibly observe some regenerative mechanism or plasticity. Our study has revealed an increase in the expression of the TrkA, TrkB and TrkC gene at 12 weeks from the administration of ASN to ST, which may confirm our suggestion about the initial regenerative or survival mechanism. Sofroniew et al. suggest that CD4+ lymphocytes are able to stimulate the expression of TrkA receptors for NGF [19]. Our results regarding TrkA, TrkB and TrkC receptors could confirm our observation about some stimulation of neurotrophins at the gene level by proinflammatory cytokines. Presumably, 12 weeks after the intoxication of ASN, a delayed regenerating mechanism starts to work, promoting the survival of neurons. This is probably the reason why the higher level of mRNA for neurotrophin receptors was observed later than the higher level of mRNA for neurotrophins. The disordering of the expression of neurotrophins can be observed in patients with long-term exposure to ASN overexpression. However, in a short time observation, we suggest that the inflammatory reaction caused by ASN monomers may increase the expression of neurotrophins and their receptors. This mechanism is intended to increase the survival of neuron cells. The full effect of the long-term ASN overexpression is still unknown. There is still a lack of information about which neuropathological mechanisms of ASN are the most severe in PD and other synucleinopathies.

In our study, we reported the T-cell infiltration to the CNS following ASN delivery to ST or SN. We observed the infiltration of T CD4+ lymphocytes Immamura et al. suggest that MHC class I and II expression led to the initiation of antigen-specific immune responses and induced T-cell infiltration of both $\mathrm{CD} 4+$ and $\mathrm{CD} 8+$ subpopulations into the CNS [48]. In the present study, after the administration of
ASN to ST or SN, CD4+ lymphocyte migration was observed in all groups. We did not observe any infiltration of CD4+ lymphocytes after the administration of $\mathrm{NaCl}$, except one week after the injection of $\mathrm{NaCl}$ into ST, which suggests that the mechanical breach of the blood-brain barrier is not the only factor affecting the migration of CD4+ cells to the CNS. A statistically significant increase in the number of CD4+ lymphocytes after ASN injection to ST or SNpc corresponds to the increased expression of the Ibal mRNA level, which is the marker of the activation of microglial cells. Similar results were demonstrated by Harms et al. [49] who investigated the effect of ASN on the lymphocyte activation. The authors observed a strong microglia stimulation and the activation of the MHC II complex induced by elevated ASN and infiltration of CD4+. The authors pointed out that the overexpression of ASN resulting from the stimulation of microglia, the induction of the MHC II complex, and the activation of antigen-presenting cells (APC) contribute to the presentation of antigen to CD4+ T-cells, resulting in the influx of this lymphocyte population to the site of damage and the release of several cytokines. Harms et al. also underline that the induction of the MHC II complex is crucial to microglial stimulation in the presence of elevated ASN concentrations. In our study we noted an increase in the number of CD4+ T lymphocytes in the CNS following the administration of ASN. Kustrimovic et al. indicate that CD4+ lymphocytes are significantly involved in initiating apoptotic nerve cell processes [50]. Probably, the activation of microglia cells induces MHC II, which contributes to the presentation of antigen to CD4+ T-cells, resulting in the infiltration of this lymphocyte population to the site of injury and the release of pro- and anti-inflammatory cytokines. In our previous work [3] we demonstrated that the injection of ASN protein was most likely to stimulate microglia. That observation was confirmed quantitatively by the Western Blot method and immunohistochemistry staining which showed numerous hyperactive microglial cells, with larger cell bodies and shorter processes. In this paper we demonstrated that the intoxication with ASN monomers resulted in the increase of the mRNA level of Iba1. In the current work, Real-Time PCR showed a significant increase in the striatal Ibal mRNA expression after 4 weeks and 12 weeks after ASN injection into ST, or 12 weeks after injecting ASN into $\mathrm{SN}$ in comparison to the corresponding $\mathrm{NaCl}$ groups. Our results confirm that the injection of ASN causes strong microglial activation at the gene transcription level. Similar summary was presented by Zhang et al. who suggested that ASN triggered an inflammatory and oxidative stress through microglial activation. Moreover, ASN stimulates microglial activation pathways and signaling [51]. Our results are in accordance with the works of other researchers (Zhang et al. [51], Hoffmann et al. [52], Alvarez-Erviti et.al. [53]) who underline the key role of ASN in the pathomechanism of the development of an inflammatory response.

Snead and Eliezer suggest that the interactions of ASN with membranes play an important role in both synuclein biology and synuclein pathology. The impaired functions of ASN and the specific mechanisms which lead to cell death and disease still remain elusive [54]. In this study, we did not observe an effect of ASN on the expression of adhesion factors ICAM-1 and VCAM-1. ICAM-1 is expressed by astrocytes in the CNS [55]. Klegeris et al. showed in their studies that the treatment of the human astrocyte cell line with ASN 
resulted in an increased expression of the ICAM-1 mRNA level. The authors observed an increase in gene expression for ICAM-1 in both wild-type ASN-treated cells and ASN with Ala30Pro or Ala53Thr mutations [44]. Etienne-Manneville et al. also suggest that astrocyte-dependent cellular adhesion initiated by ICAM-1 may contribute to the development of inflammatory processes observed during leukocyte infiltration of the CNS. In the CNS, astrocytes play a key role in immunological and inflammatory responses through ICAM-1 expression, cytokine secretion, and the regulation of blood-brain barrier permeability [56]. Halliday and Stevens suggest that the accumulation of ASN in astrocytes might damage these cells in SN [1]. There is no literature on the effect of ASN on VCAM-1 expression. In the current study we showed that ASN did not change the expression of the VCAM1 adhesive molecule in comparison to the corresponding $\mathrm{NaCl}$ group. It is assumed that after the activation, leukocytes bind to endothelial cells through the ICAM-1 / LFA-1 signaling pathway (lymphocyte function-associated antigen 1 - integrin, connecting ICAM-1 with APC cells, responsible for adhesion and migration of $\mathrm{T}$ lymphocytes), and then migrate to the tissues [37]. Akiyama $\mathrm{H}$ et al. suggest that the LFA-1/ICAM-1 system appears to play an important role in the interaction of astrocytes and microglia in several neurological diseases [57]. In our research we observed a significant infiltration of T lymphocytes. The administration of ASN did not increase the expression of adhesion molecules VCAM-1 and ICAM-1 compared to the corresponding $\mathrm{NaCl}$ groups. It can be assumed that ASN did not directly affect the expression of adhesion molecules, which may suggest that ASN has no impact on the ICAM-1 LFA-1 signaling pathway-dependent permeability of blood vessels. Moreover, it is not excluded that ASN may suppress the expression of adhesion molecule genes by suppressing the astrogliosis. Our previous results suggest that both microglial activation and suppressing astrocytes play a crucial role in ASN-related dopaminergic neurotoxicity. In the current study, after ASN intoxication, we observed microglial activation and strong infiltration of CD4+ T lymphocytes. Perhaps the lack of a significant ASN effect on the change in the concentration of adhesion factors results from the possible suppression of astrocytic cells due to the increased concentration of ASN monomer. Some speculation that astrogliosis might be suppressed in PD by ASN accumulation was published by Halliday and Stevens [1], and Tong et al.[58]. Suppressing astrocytes may have been one of the reasons why we did not observe any changes in the level of mRNA for adhesion molecules ICAM-1 and VCAM-1. On the other hand, the recruitment of lymphocytes was also possible with the use of chemokines. Thornton et al. pointed out that the expression of chemokines at the brain endothelium contributes to the neutrophil recruitment [59]. Further studies are required to reveal the detailed mechanisms of infiltration of lymphocytes into the CNS after injection of ASN.

\section{CONCLUSIONS}

Our results support the hypothesis of pro-inflammatory actions of ASN monomers. Injection of ASN into ST or SN induces microglia activation without a prominent increase of the ICAM-1 and VCAM-1 mRNA expression. These results suggest that ASN could enhance the infiltration of lymphocytes $\mathrm{T}$ without an increase of expression of adhesion molecules. In our study, we also demonstrated an increase in the expression of the BDNF, GDNF, NGF, NT-3, TrkA, TrkB and TrkC gene following the administration of ASN, which may confirm some suggestions that it initiates the regenerative or survival mechanism of neuronal cells.

\section{Acknowledgments}

This study was supported by Grant No. N N401 066638 from the Ministry of Science and Higher Education, Warsaw, Poland.

Project implemented with CePT infrastructure financed by the European UnionThe European Regional Development Fund within the operational program "Innovative economy" for 2007-2013.

\section{REFERENCES}

1. Halliday GM,Stevens CH. Glia: initiators and progressors of pathology in Parkinson's disease. Mov Disord. 2011; 26: 6-17.

2. Sanchez-Guajardo V, Tentillier N, Romero-Ramos M. The relation between a-synuclein and microglia in Parkinson's disease: Recent developments. Neuroscience. 2015; 302: 47-58.

3. Sznejder-Pacholek A, Joniec-Maciejak I, Wawer A, Ciesielska A, Mirowska-Guzel D. The effect of alpha-synuclein on gliosis and ILlalpha, TNFalpha, IFNgamma, TGFbeta expression in murine brain. Pharmacol Rep. 2017; 69: 242-251.

4. Gardai SJ, Mao W, Schule B, Babcock M, Schoebel S, Lorenzana C, et al. Elevated alpha-synuclein impairs innate immune cell function and provides a potential peripheral biomarker for Parkinson's disease. PLoS One. 2013; 8: e71634.

5. Reynolds AD, Glanzer JG, Kadiu I, Ricardo-Dukelow M, Chaudhuri A, Ciborowski P, et al. Nitrated alpha-synuclein-activated microglial profiling for Parkinson's disease. J Neurochem. 2008; 104: 1504-25.

6. Beraud D, Hathaway HA, Trecki J, Chasovskikh S, Johnson DA, Johnson JA, et al. Microglial activation and antioxidant responses induced by the Parkinson's disease protein alpha-synuclein. J Neuroimmune Pharmacol. 2013; 8: 94-117.

7. Sacino AN, Brooks M, McKinney AB, Thomas MA, Shaw G, Golde TE, et al. Brain Injection of alpha-Synuclein Induces Multiple Proteinopathies, Gliosis, and a Neuronal Injury Marker. J Neurosci. 2014; 34: 12368-78.

8. Lin LF, Doherty DH, Lile JD, Bektesh S, Collins F. GDNF: a glial cell line-derived neurotrophic factor for midbrain dopaminergic neurons. Science. 1993; 260: 1130-2.

9. Cheng FC, Ni DR, Wu MC, Kuo JS, Chia LG. Glial cell line-derived neurotrophic factor protects against 1-methyl-4-phenyl-1,2,3,6tetrahydropyridine (MPTP)-induced neurotoxicity in C57BL/6 mice. Neurosci Lett. 1998; 252: 87-90.

10. Kells AP, Eberling J, Su X, Pivirotto P, Bringas J, Hadaczek P, et al. Regeneration of the MPTP-lesioned dopaminergic system after convection-enhanced delivery of AAV2-GDNF. Journal of Neuroscience. 2010; 30: 9567-9577.

11. Gill SS, Patel NK, Hotton GR, O’Sullivan K, McCarter R, Bunnage M, et al. Direct brain infusion of glial cell line-derived neurotrophic factor in Parkinson disease. Nat Med. 2003; 9: 589-95.

12. Ciesielska A, Mittermeyer G, Hadaczek P, Kells AP, Forsayeth J, Bankiewicz KS. Anterograde Axonal Transport of AAV2-GDNF in Rat Basal Ganglia. Molecular Therapy. 2011; 19: 922-927.

13. Hyman C, Hofer M, Barde YA, Juhasz M, Yancopoulos GD, Squinto $\mathrm{SP}$, et al. BDNF is a neurotrophic factor for dopaminergic neurons of the substantia nigra. Nature. 1991; 350: 230-2.

14. Alderson RF, Alterman AL, Barde YA, Lindsay RM. Brain-derived neurotrophic factor increases survival and differentiated functions of rat septal cholinergic neurons in culture. Neuron. 1990; 5: 297-306.

15. Bekinschtein P, Cammarota M, Izquierdo I, Medina JH. BDNF and memory formation and storage. Neuroscientist. 2008; 14: 147-56.

16. Alonso M, Vianna MR, Depino AM, Mello e Souza T, Pereira P, Szapiro $\mathrm{G}$, et al. BDNF-triggered events in the rat hippocampus are required for both short- and long-term memory formation. Hippocampus. 2002; 12: $551-60$. 
17. Weinstein G, Beiser AS, Choi SH, Preis SR, Chen TC, Vorgas D, et al. Serum brain-derived neurotrophic factor and the risk for dementia: the Framingham Heart Study. JAMA Neurol. 2014; 71: 55-61.

18. Diniz BS,Teixeira AL. Brain-derived neurotrophic factor and Alzheimer's disease: physiopathology and beyond. Neuromolecular Med. 2011; 13: 217-22.

19. Sofroniew MV, Howe CL, Mobley WC. Nerve growth factor signaling, neuroprotection, and neural repair. Annu Rev Neurosci. 2001; 24 : $1217-81$.

20. Nico B, Mangieri D, De Luca A, Corsi P, Benagiano V, Tamma R, et al Nerve growth factor and its receptors TrkA and p75 are upregulated in the brain of mdx dystrophic mouse. Neuroscience. 2009; 161: 1057-1066.

21. Kaplan DR, Miller FD. Signal transduction by the neurotrophin receptors. Curr Opin Cell Biol. 1997; 9: 213-21.

22. Santos NAG, Martins NM, Sisti FM, Fernandes LS, Ferreira RS, Queiroz RHC, et al. The neuroprotection of cannabidiol against MPP+-induced toxicity in PC12 cells involves trkA receptors, upregulation of axonal and synaptic proteins, neuritogenesis, and might be relevant to Parkinson's disease. Toxicology in Vitro. 2015; 30: 231-240.

23. Lau YS, Patki G, Das-Panja K, Le WD, Ahmad SO. Neuroprotective effects and mechanisms of exercise in a chronic mouse model of Parkinson's disease with moderate neurodegeneration. Eur J Neurosci. 2011; 33: 1264-74.

24. Tuon T, Valvassori SS, Dal Pont GC, Paganini CS, Pozzi BG, Luciano TF, et al. Physical training prevents depressive symptoms and a decrease in brain-derived neurotrophic factor in Parkinson's disease. Brain Res Bull. 2014; 108: 106-12.

25. Sobue G, Yamamoto M, Doyu M, Li M, Yasuda T, Mitsuma T. Expression of mRNAs for neurotrophins (NGF, BDNF, and NT-3) and their receptors ( $\mathrm{p} 75 \mathrm{NGFR}$, trk, trkB, and trkC) in human peripheral neuropathies. Neurochem Res. 1998; 23: 821-9.

26. Besser M,Wank R. Cutting edge: clonally restricted production of the neurotrophins brain-derived neurotrophic factor and neurotrophin-3 mRNA by human immune cells and Th1/Th2-polarized expression of their receptors. J Immunol. 1999; 162: 6303-6.

27. Egan MF, Kojima M, Callicott JH, Goldberg TE, Kolachana BS, Bertolino A, et al. The BDNF val66met polymorphism affects activity-dependent secretion of BDNF and human memory and hippocampal function. Cell. 2003; 112: 257-69.

28. Hudson J, Granholm AC, Gerhardt GA, Henry MA, Hoffman A, Biddle $\mathrm{P}$, et al. Glial cell line-derived neurotrophic factor augments midbrain dopaminergic circuits in vivo. Brain Res Bull. 1995; 36: 425-32.

29. Cai J, Hua F, Yuan L, Tang W, Lu J, Yu S, et al. Potential Therapeutic Effects of Neurotrophins for Acute and Chronic Neurological Diseases. Biomed Res Int. 2014; 2014: 601084.

30. Kerschensteiner M, Gallmeier E, Behrens L, Leal VV, Misgeld T, Klinkert WE, et al. Activated human T cells, B cells, and monocytes produce brain-derived neurotrophic factor in vitro and in inflammatory brain lesions: a neuroprotective role of inflammation? J Exp Med. 1999; 189: $865-70$

31. Heese K, Fiebich BL, Bauer J, Otten U. NF-kappaB modulates lipopolysaccharide-induced microglial nerve growth factor expression. Glia. 1998; 22: 401-7.

32. Imamura K, Hishikawa N, Ono K, Suzuki H, Sawada M, Nagatsu $\mathrm{T}$, et al. Cytokine production of activated microglia and decrease in neurotrophic factors of neurons in the hippocampus of Lewy body disease brains. Acta Neuropathol. 2005; 109: 141-50.

33. McGeer PL,McGeer EG. Glial reactions in Parkinson's disease. Mov Disord. 2008; 23: 474-83.

34. Mizuma H, Takagi K, Miyake K, Takagi N, Ishida K, Takeo S, et al. Microsphere embolism-induced elevation of nerve growth factor level and appearance of nerve growth factor immunoreactivity in activated T-lymphocytes in the rat brain. J Neurosci Res. 1999; 55: 749-61.

35. Barouch R, Appel E, Kazimirsky G, Braun A, Renz H, Brodie C. Differential regulation of neurotrophin expression by mitogens and neurotransmitters in mouse lymphocytes. J Neuroimmunol. 2000; 103: $112-21$.

36. Kurkowska-Jastrzebska I, Wronska A, Kohutnicka M, Czlonkowski A, Czlonkowska A. The inflammatory reaction following 1-methyl-4phenyl-1,2,3, 6-tetrahydropyridine intoxication in mouse. Exp Neurol. 1999; 156: 50-61.

37. Yang L, Froio RM, Sciuto TE, Dvorak AM, Alon R, Luscinskas FW. ICAM-1 regulates neutrophil adhesion and transcellular migration of TNF-alpha-activated vascular endothelium under flow. Blood. 2005; 106: 584-92.
38. Wu L, Walas S, Leung W, Sykes DB, Wu J, Lo EH, et al. Neuregulin1beta Decreases IL-1beta-Induced Neutrophil Adhesion to Human Brain Microvascular Endothelial Cells. Transl Stroke Res. 2014.

39. Pfaffl MW. A new mathematical model for relative quantification in real-time RT-PCR. Nucleic Acids Res. 2001; 29: e45.

40. Nagatsu T, Mogi M, Ichinose H, Togari A. Cytokines in Parkinson's disease. J Neural Transm Suppl. 2000: 143-51.

41. Baba Y, Kuroiwa A, Uitti RJ, Wszolek ZK, Yamada T (2005) Alterations of T-lymphocyte populations in Parkinson disease vol 11, 2005/09/13 edn. doi:10.1016/j.parkreldis.2005.07.005

42. Brodacki B, Staszewski J, Toczylowska B, Kozlowska E, Drela N, Chalimoniuk M, et al. Serum interleukin (IL-2, IL-10, IL-6, IL-4), TNFalpha, and INFgamma concentrations are elevated in patients with atypical and idiopathic parkinsonism. Neurosci Lett. 2008; 441: 158-62.

43. Rentzos M, Nikolaou C, Andreadou E, Paraskevas GP, Rombos A, Zoga $\mathrm{M}$, et al. Circulating interleukin-10 and interleukin-12 in Parkinson's disease. Acta Neurol Scand. 2009; 119: 332-7.

44. Klegeris A, Giasson BI, Zhang H, Maguire J, Pelech S, McGeer PL. Alpha-synuclein and its disease-causing mutants induce ICAM-1 and IL-6 in human astrocytes and astrocytoma cells. Faseb j. 2006; 20: 2000-8.

45. Yuan Y, Sun J, Zhao M, Hu J, Wang X, Du G, et al. Overexpression of alpha-synuclein down-regulates BDNF expression. Cell Mol Neurobiol. 2010; 30: 939-46.

46. Adamczyk A, Kazmierczak A, Czapski GA, Strosznajder JB. Alphasynuclein induced cell death in mouse hippocampal (HT22) cells is mediated by nitric oxide-dependent activation of caspase-3. FEBS Lett. 2010; 584: 3504-8.

47. Nishiguchi M, Tokugawa K, Yamamoto K, Akama T, Nozawa Y, Chaki S, et al. Increase in secretion of glial cell line-derived neurotrophic factor from glial cell lines by inhibitors of vacuolar ATPase. Neurochemistry International. 2003; 42: 493-498.

48. Imamura K, Hishikawa N, Sawada M, Nagatsu T, Yoshida M, Hashizume Y. Distribution of major histocompatibility complex class II-positive microglia and cytokine profile of Parkinson's disease brains. Acta Neuropathol. 2003; 106: 518-26.

49. Harms AS, Cao S, Rowse AL, Thome AD, Li X, Mangieri LR, et al. MHCII is required for alpha-synuclein-induced activation of microglia, CD4 $\mathrm{T}$ cell proliferation, and dopaminergic neurodegeneration. J Neurosci. 2013; 33: 9592-600.

50. Kustrimovic N, Rasini E, Legnaro M, Marino F, Cosentino M. Expression of dopaminergic receptors on human CD4+ T lymphocytes: flow cytometric analysis of naive and memory subsets and relevance for the neuroimmunology of neurodegenerative disease. J Neuroimmune Pharmacol. 2014; 9: 302-12.

51.Zhang Q-S, Heng Y, Yuan Y-H, Chen N-H. Pathological $\alpha$-synuclein exacerbates the progression of Parkinson's disease through microglial activation. Toxicology Letters. 2017; 265: 30-37.

52. Hoffmann A, Ettle B, Bruno A, Kulinich A, Hoffmann A-C, von Wittgenstein J, et al. Alpha-synuclein activates BV2 microglia dependent on its aggregation state. Biochemical and Biophysical Research Communications. 2016; 479: 881-886.

53. Alvarez-Erviti L, Couch Y, Richardson J, Cooper JM, Wood MJA. Alphasynuclein release by neurons activates the inflammatory response in a microglial cell line. Neuroscience Research. 2011; 69: 337-342.

54. Snead D,Eliezer D. Alpha-synuclein function and dysfunction on cellular membranes. Exp Neurobiol. 2014; 23: 292-313.

55. Lee SJ, Drabik K, Van Wagoner NJ, Lee S, Choi C, Dong Y, et al. ICAM1-induced expression of proinflammatory cytokines in astrocytes: involvement of extracellular signal-regulated kinase and p38 mitogenactivated protein kinase pathways. J Immunol. 2000; 165: 4658-66.

56. Etienne-Manneville S, Chaverot N, Strosberg AD, Couraud PO. ICAM1 -coupled signaling pathways in astrocytes converge to cyclic AMP response element-binding protein phosphorylation and TNF-alpha secretion. J Immunol. 1999; 163: 668-74.

57. Akiyama H, Kawamata T, Yamada T, Tooyama I, Ishii T, McGeer PL. Expression of intercellular adhesion molecule (ICAM)-1 by a subset of astrocytes in Alzheimer disease and some other degenerative neurological disorders. Acta Neuropathol. 1993; 85: 628-34.

58. Tong J, Ang LC, Williams B, Furukawa Y, Fitzmaurice P, Guttman M, et al. Low levels of astroglial markers in Parkinson's disease: relationship to alpha-synuclein accumulation. Neurobiol Dis. 2015; 82: 243-253.

59. Thornton P, McColl BW, Greenhalgh A, Denes A, Allan SM, Rothwell NJ. Platelet interleukin-1a drives cerebrovascular inflammation. Blood. 2010; 115: 3632-3639. 